\title{
INCREASINGLY OVERLAPPING MAGISTERIA OF SCIENCE AND RELIGION
}

\author{
CHARLES H LINEWEAVER \\ Planetary Science Institute, Research School of Astronomy and \\ Astrophysics and Research School of Earth Sciences, The Australian \\ National University, Canberra, ACT, 0200 Australia
}

\section{Science and Religion: Separate Magisteria?}

As explorers, missionaries and anthropologists of literate tribes came in contact with preliterate tribes, we found out that every human tribe has religious ideas about gods, the supernatural and ethics. We can conclude from this that having some kind of religion is a universal part of human nature (Brown 1991). However, to be a scientist means depriving ourselves of the traditional inclination to invoke supernatural explanations for natural events. Scientists cannot invoke gods to explain mountains, lightning, stars, volcanoes, rain, birth, death or any other of the natural events that are part of our lives. But what about the origin of the universe and its laws, the origin of ethics and the purpose of life? Does science have a role to play in explaining these? Or are these phenomena within the exclusive domain of religion?

Occasionally scientists reflect on the relationship between science and religion (Townes 1966, Feynman 1999, Weinberg 2001) and debate whether our understanding of nature can help us make moral decisions or tell us how we ought to behave (Huxley 1894, Williams 1988ab). In Rock of Ages (1999) Stephen Jay Gould defends the idea that science and religion reign over separate conceptual kingdoms-separate "magisteria". The magisteria of science covers empirical facts: What is the universe made of? How does it behave? While the magisteria of religion extends over "the search for proper ethical values and the spiritual meaning of our lives.” (Gould 1997). Gould calls this conceptual segregation "NOMA" (= Non Overlapping MAgisteria).

"Science can work only with naturalistic explanations; it can neither affirm nor deny other types of actors (like God) in other spheres (the moral realm, for example).” (Gould 1992)

According to Gould science can tell us how the heavens go, not how to go to heaven. Science can tell us how we behave not how we should behave. Science can tell us what is, not what ought to be. Science is descriptive, not prescriptive. Apparently, we cannot rely on science for all the answers. We must turn to a religion and a holy book or we must look inside ourselves and ask our consciences how we should behave.

Gould is not alone in this opinion: 
"Facts do not constitute a criterion for the judgment of the moral content of human acts." (Cardinal Joseph Ratzinger, 1970, head of The Vatican's Congregation for the Propagation of the Faith)

From science, one "will never obtain a proposition which says: do this, or do not do that; that is to say a proposition which confirms or contradicts ethics."

(Gillispie 1973)

"The evaluation of moral codes or human actions must take into account biological knowledge. But for deciding which moral codes should be accepted, biology alone is palpably insufficient.” (Ayala 1987)

Theologian John Haught's testimony against Intelligent Design being taught in Pennsylvania schools, was an expression of NOMA:

"In deliberately omitting theological or "ultimate" explanations for the existence or characteristics of the natural world, science does not consider issues of "meaning” and "purpose” in the world." (Kitzmiller v. Dover Area School District 2005)

Critics of, and commentators on Gould's NOMA include Hall (1999), Dennett (2006) and me (this article):

"Gould is right, of course, that there should be no conflict, since, from the religious point of view, anything that science finds to be the probable truth about how things actually are, can be incorporated into religion by just saying "that's how God did it;" and, from the scientific point of view, all of the religious talk about "souls" and "afterlife" is as meaningful as the story of Frodo's voyage to the Gray Havens." (Hall, 1999)

“Although Gould's desire for peace between these often warring perspectives was laudable, his proposal found little favor on either side, since in the minds of the religious it proposed abandoning all religious claims to factual truth and understanding of the natural world (including claims that God created the universe, or performs miracles or listens to prayers) whereas in the minds of the secularists it granted too much authority to religion in matters of ethics and meaning.” (Dennett 2006, p 30)

As science begins to address more fundamental and previously taboo issues (the origin of the universe, the origin of life, the origin and evolution of humanity, the evolutionary biology of human nature, sexuality, consciousness and morality), the magisteria of science expands and increasingly overlaps with the traditional monopoly that religion has had on these areas. Big bang cosmology and Darwinian evolution are revolutionary scientific ideas that have replaced our traditional religious conceptions of the origin of the world and the origin of humanity. 
Science also makes large contributions to our search for "proper ethical values”. For example, anthropologists studying other cultures often open our minds to the morals of other cultures. Margaret Mead's book "Coming of Age in Samoa” (1928) showed us that there are other acceptable ways to raise children and this knowledge changed our behavior. Science has an important voice in many areas that have been taboo to scientific inquiry. The scientific study of human sexuality removed much of the guilt associated with supposedly (but not in actuality) deviant sexual behavior (Kinsey 1953, Masters and Johnson 1966). As scientific studies explore more issues and find out how we behave, our view of ourselves changes and this often changes how we think we should behave. The is and the ought cannot be confined to separate realms.

\section{Divine Action and Gods of the Gaps.}

Religions of literate societies have tried hard to distance themselves from the animistic traditions from which they emerged because these traditional superstitions were in obvious conflict with emerging scientific understanding of lightning, thunder, earthquakes, volcanoes, what goes on at the top of mount Olympus and what pulls the Sun across the sky. Many expressions of religious philosophy accept scientific knowledge of the empirical world, but try to carve out areas in which science has no validity. The areas in which religion is held to have superior knowledge include knowledge of the spirit, the soul, the origin and purpose of human life and ethics. As scientific explanatory power increases, science begins to have something to say about these areas (more in some than others). Religious explanations become marginalized and confined to gaps. The phrase 'God of the gaps' was coined by Coulson (1958) to describe this process.

It is difficult, however, to sustain religious descriptions of the physical world, in which god (or gods) act as a cause complementing physical causes (divine action) -filling in the gaps left by scientific explanations (Saunders 2002). Acceptance that force could act at a distance eliminated the need for gods to mediate the force of gravity. An understanding of Darwinian evolution eliminated the need for gods to create people and more generally eliminated the need for gods to design each creature individually.

On the other hand, although biochemistry and genetics indicate that the molecules of life are made of normal atoms and behave according to the laws of chemistry, we still don't understand the origin of life very well; so there is a gap for gods there to breathe the breath of life or "elan vital" into the living. We also do not understand the origin of the laws of physics at all so there is a really big gap there.

At the Vatican cosmology conference in 1981, Pope John Paul II addressed the attendees. White and Gribbin (2002) described the proceedings:

"[T]he Pope warned the physicists against delving too deeply into the question of how or why the Universe began, reminding them that this was solely a matter for theologians. He went on: Any scientific hypothesis on the origin of the world, such as that of the primeval atom from which the whole of the physical world derived, leaves open the problem concerning the beginning of the Universe. Science cannot by itself resolve such a question; what is needed is that human 
knowledge that rises above physics and astrophysics which is called metaphysics; it needs above all the knowledge that comes from the revelation of God. Hawking sat impassively in his wheelchair listening."

It was at this 1981 Vatican conference that Hawking announced his controversial "noboundary" theorem; a scientific attempt to explain the origin of the universe; precisely what the Pope was warning against. The magisteria of science seems to be expanding and overlapping increasingly with the magisteria of religion.

\section{Biology-based Ethics?}

Nature is "neither moral nor immoral, but non-moral” (Huxley 1894).

“Although during his career he [Thomas H. Huxley] contributed energetically to the advance of Darwinism, he came at last to perceive an impossible cleavage between the Darwinian view of nature "red in tooth and claw" and human values. Finding it impossible to reconcile the two, he abandoned the quest for a comprehensive evolutionary world view.” (Oates 1988).

Huxley's focus on "red in tooth and claw" competition meant that Darwinian evolution could not explain the development of human values. The dilemma Huxley faced was not, however, irresolvable. Current research seems to be uncovering the large, but less explicit contribution that cooperation makes to adaptation and survival (Ridley 1997, Sober and Wilson 1998, see however Williams 1988ab).

The evolutionary origins of human behavior and the evolutionary approach to ethics are the subject of much research and debate: (Darwin 1871; Williams 1966, 1988ab, Wilson 1976, 1978, Hamilton 1975; 1998, Dawkins 1976; Ayala 1987, Barkow et al 1992 , Ridley 1996, Sober and Wilson 1998, Lieberman et al 2003 and references therein). Leading evolutionary biologists have argued that selection has "shaped" human morality. The extent of that "shaping" is a scientific question that can be addressed with difficulty, but has important consequences for our view of ourselves and how we think we should behave (Pinker 2002).

"The biologist, who is concerned with questions of physiology and evolutionary history, realizes that self-knowledge is constrained and shaped by the emotional control centers in the hypothalamus and limbic system of the brain. These centers flood our consciousness with all the emotions, hate, love, guilt, fear, and othersthat are consulted by ethical philosophers who wish to intuit the standards of good and evil. What, we are then compelled to ask, made the hypothalamus and limbic system? They evolved by natural selection.” (Wilson 1975)

Sociobiology is the systematic study of the biological basis of all social behavior (Wilson 1975). This study can and should be used to help us modify our behavior. If we can understand how our "oughts" came to be inside our heads, then we can look at ourselves and reevaluate what our "oughts” ought to be. There are scientific facts about 
being human (Wilson 1978) which are important and have important moral implications that help me (and many others) make moral decisions about how to behave. See Bleier (1984) for a criticism of this sociobiological program.

Incest taboos (Jones 1997, Lieberman et al 2003) produce ethical decisions about who we ought and ought not, to marry. The origins of these taboos can be understood as the result of an evolutionary selection to eliminate inbreeding and troublesome double recessive genes. Thus, the scientific understanding of the reasons for taboos tell us how we should behave and why. We can modify our behavior to avoid the real problems. We are not left blind with the procrustean fears induced by our traditional supernatural narratives.

Food taboos can also sometimes be explained scientifically. The scientific understanding of trichinosis and the undoing of the taboo against eating pork is an example. Roadside police making scientific measurements of alcohol blood levels is a graphic example of science determining how much you should drink. But this is not a moral issue is it? Are we dealing with a moving target? i.e. once science has understood a phenomenon and determined how one should act in a given situation to minimize harm (who to marry, how to prepare food, how much to drink), are our decisions to act rationally no longer classified as "moral decisions"? If so, then by definition, this excludes science from influencing "moral" behavior and is equivalent to a moraldecisions-of-the-gaps approach.

Ethical values and a sense of meaning are the products of natural selection. Our ideas of "good" and "evil", and our consciences that we rely on to help us make moral decisions (like Pinnochio's Jiminy Cricket), are features of consciousness that have evolved under selection pressure, just like skin color, intestinal $\mathrm{pH}$ and fingernail growth rates. The fact that moral decision-making is complex and contextual does not mean that the process - like our other brain functions - did not evolve (Barkow et al 1992, Pinker 2002). This being so, we can try to understand their origin, why they are there, what purpose they serve and based on this information decide how we should behave. Even speculative explorations of evolutionary psychology give us a better (or at least a complementary) understanding of ourselves than Moses-went-up-to-the-mountain-andcame-down-with-some-rules-that-we-are-supposed-to-follow-because-God-said-so explanations of human ethics.

\section{The Origin of Life, High Expectations and Looking for a Purpose}

"It is mere rubbish, thinking at present of the origin of life; one might as well think of the origin of matter." (Darwin 1863)

The magisteria of science has expanded since Darwin's time. Studies of the origin of matter (baryogenesis), is one of the most important topics in modern cosmology (e.g. Sahkarov 1967, Kolb and Turner 1990). And studies of the origin of life (biogenesis) is one of the most important fields of modern biology (e.g. Schroedinger 1944, Fox 1986, de Duve 1995, Lahav 1999), and has spawned the new science of astrobiology (e.g. Seckbach et al 2004, Lunine 2005, Hazen 2006). 
What about purpose? The first thing we need to know about purpose is: Why do we want to find one? Here are three quotes about purpose from a fundamentalist Christian, a movie star and a nobel prize winner in physics that point to an answer.

"Darwinian theory of evolution contradicts not just the Book of Genesis, but every word in the Bible from beginning to end. It contradicts the idea that we are here because a creator brought about our existence for a purpose."

(quote from Johnson 1991, cited in Kitzmiller v. Dover Area School District 2005)

"Nature, Mr. Alnutt, is what we were put in this world to rise above."

(Katharine Hepburn to Humphrey Bogart in the 1951 film "The African Queen")

"Below the Earth looks very soft and comfortable - fluffy clouds here and there, snow turning pink as the Sun sets, roads stretching straight across the country from one town to another. It is very hard to realize this all is just a tiny part of an overwhelmingly hostile Universe. It is even harder to realize that this present Universe has evolved from an unspeakably unfamiliar early condition, and faces a future extinction of endless cold or intolerable heat. The more the Universe seems comprehensible, the more it also seems pointless.” (Weinberg 1977)

Thirteen years later Weinberg reflected further on his reflections:

"If you say things are pointless, you have to ask, 'Well, what point were you looking for?’” (Lightman and Brawer 1990 p 466)

The universe is only pointless to the degree that we insist it have a point. Our expectations, not the universe, are to blame for the apparent pointlessness. We have high hopes for top billing-hopes to see our names writ large on the universe, above nature and at the express orders of the gods. Real observations of nature cannot compete with such expectations. We are left disappointed. Expectations high enough can always preclude one from accepting objective facts not specifically constructed to boost our egos. In many ways, scientific observations engender in us a sense of humility about our position in the universe. This is another way in which science shapes our self-opinion and shapes our moral stance with respect to the Earth and universe.

Believing you have a purpose is probably adaptive. It makes you feel worth something and increases self-esteem. However, it also produces vanity and eventually disappointment when science finds out (as it inevitably keeps finding out) that the universe does not rotate around us. The resultant disappointment is seen in Steven Weinberg's casual comments about the pointlessness of the universe, in the fundamentalist Christian's irate anti-Darwinism and in Hepburn's pre-Darwinian airs about humanity belonging above nature. Human beings apparently need a sense of purpose.

"[E]ven a "scientific" world view must answer the needs of the human mind for a sense of order and meaning. It is not enough to offer the intellect a vision of how the whole is put together. It must also offer the emotions a sense of belonging, the imagination a sense of delight, the heart a sense of goodness. These are much of 
what distinguish a world view from mere theory or speculation. And the skill with which these affective elements are integrated with the intellectual and empirical is certainly one of the crucial measures of a world view's power-in Darwin's day, in Huxley’s and in our own.” (Oates 1988)

The expectation that humans have a more noble purpose that matters in the grand scheme of things, is not easily jettisoned. Expectations exist for a reason. We are life forms that have been specifically selected to harbor the adaptive belief that we are important. Thinking that you are worth more than the thing you need to kill to stay alive has adaptive value. Evolutionary psychologists might explain that encephalated heterotrophs who did not believe this have gone extinct for lack of psychological reinforcements. Natural selection of encephalated beings has as much to do with selecting adaptive ideas as it has to do with physical adaptiveness. In large-brained beings, the survival of genes and memes are correlated (Dennett 2006). I look to science to help me understand why we think that humans are worth more than other species, and why my in-group, my nation, my culture is better than other groups, nations and cultures. The current scientific debate over group selection may help answer some of these questions (e.g. Sober and Wilson 1998). For a perceptive discussion of the status of such adaptive explanations, see Gray et al (2003).

\section{Is the Purpose of Life The Production of Entropy?}

Another topic within the traditionally religious magisteria is the purpose of life. In contrast to most scientists, I think that science has a lot to say about it. If one gives up the idea that human beings are somehow special and have a purpose that is different from other life, one is free to explore the question without fear of disappointment.

Dawkins articulated the case for the purpose of life as the promotion of the survival of selfish genes:

"We are survival machines - robot vehicles blindly programmed to preserve the selfish molecules known as genes. This is a truth which still fills me with astonishment.” (Richard Dawkins in the preface of The Selfish Gene 1976)

But if our purpose is to preserve genes, what is the purpose of the genes? If selfpreservation is their purpose, where did this purpose come from? Where did the information in the genes come from that promotes this purposeful activity?

All of the information content of genes came from the environment, i.e. from the selection pressures, on molecules, of the architectural complexity of a low entropy environment (e.g. Fox 1986). A low entropy state seems to have been the initial state of the universe (Frautschi 1982, Lineweaver 2005). In an environment in equilibrium, without structure -- without specific chemical free energy gradients, no information could be inserted into genes - no information could be extracted by genes - because there would be no information. There would be no selection pressure --no advantage to one type of behavior over another. No purposefulness could evolve in the form of selfpreserving genes. Life requires non-equilibrium. You can't get into the self-preservation 
business in the first place without a structured, information-rich environmental architecture to push you around in specific ways. Without free energy gradients, life in particular, and far from equilibrium dissipative structures ("FEDS") in general, are not possible. With such gradients, FEDS (in general) are inevitable. We see them everywhere in the universe. Whether free energy gradients inevitably produce the type of FEDS called life is an open question (Prigogine 1980, Prigogine and Stengers 1984, Schneider and Kay 1994, Schneider 2004, Schneider and Sagan 2005).

Given a low entropy environment, there will be lots of structure, lots of free energy and the second law of thermodynamics will spontaneously create FEDS which seem to have as their "purpose" (at least that is what they do) the production of entropy over and above the amount of entropy that would be produced in their absence by diffusion and other relaxation processes. These far from equilibrium dissipative structures (galaxies, stars, convection cells, hurricanes, whirlpools, life forms) promote the flow of material, and heat and reduce gradients (Lineweaver 2006). To take seriously the idea that the purpose of life is to increase the entropy of the universe we need to show that the second law holds in far from equilibrium situations. This is not straight-forward (Dewar 2003, 2005, Kleidon and Lorenz 2005) however it seems to be the most reasonable working assumption.

Dawkins tells us that it's not people who are in control of their destiny, it is the selfish genes who control us. But one can also postulate that genes are not selfish. Genes are the unwitting pawns of the second law, which has conjured them up to increase the entropy of the universe, much as the genes, in their turn, have conjured us up to do their bidding. Thus we can take Dawkins' logic one step further and propose that:

Genes are entropy machines - robot vehicles blindly programmed to increase a quantity known as entropy. This is a tentative truth which is beginning to fill me with astonishment.

Purposes are linked to origins, and finding out the origins of life; what prerequisites drove life to become what it is; can go far --possibly as far as one can go -- towards revealing purpose. The "purpose" of a hurricane is to reduce the pressure and temperature gradients and increase entropy (at least that is what it does). The "purpose" of a convection cell is to reduce the temperature gradient faster than diffusion would allow and increase entropy. In the same sense, I suspect that the "purpose" of life is the same as these other far from equilibrium dissipative structures: to reduce gradients and increase entropy. The fact that this "purpose" does not conform to the type of answer we want and expect increases my confidence in its validity because it has not been constructed to flatter us. See Sagan and Whitesides (2004), Schneider and Sagan (2005), Schneider and Kay (1994).

A convection cell is nature's way of reducing a thermal gradient, or nature's way of increasing the entropy of the universe faster than it would without the existence of a convection cell. Thermal gradients produce convection cells and these convection cells reduce thermal gradients. There is a chronological order here. The same chronological order was followed when chemical gradients produced proto-life, proto-life reduced chemical gradients and along the way, proto-life centralized some information and became life, free to search out chemical gradients to survive off of. 


\section{Ancestors become Food}

Complex structures form whenever there is an energy gradient to drive them. It is appealing and possibly useful that the "purpose" of these structures is to get rid of the gradient that produced it. That is, the purpose of these structures is to increase the entropy of their environments.

The second law of thermodynamics brings about spontaneously the existence of far from equilibrium dissipative systems "to reduce” (or "that reduce”) free energy gradients. One of those systems (life) learned how to centralize some information (genes) and learned how to reproduce itself. With this autonomy it could actively seek out the chemical free energy gradients. Gradients which were needed for its existence now could be actively sought. Today life sees free energy gradients as food, rather than ancestors. Self-preservation became a more important goal than the original goal of gradient reduction. Gradient reduction became a secondary goal or by-product of its selfpreservative activity. The origin of life and the original purpose of life are connected by the second law. Life's new purpose is preservation. But life still shares its primary purpose with convection cells, stars, hurricanes and other far from equilibrium dissipative systems - and that purpose is the reduction of gradients and the production of entropy.

Consider the following two hypotheses:

1) Entropy production is a by-product of life (usual assumption)

2) Life is a by-product of entropy production

The first places life at the center while the second gives primacy to entropy production. I am arguing qualitatively for 2), that the entropy production of the second law is the driving force responsible for the origin of FEDS and life. But, I'm not sure these ideas are precise enough to test quantitatively. Could both be true? Consider two more hypotheses:

a) An egg is a chicken's way of making another chicken (usual assumption)

b) A chicken is an egg's way of making another egg

There is an attractive symmetry here that leads one to say that both could be correct. The real difficulty for those who seek "purpose" lies in the unanswered question: Who is "in control"? Who is the "active agent"? In the absence of a way to determine the "active agent" we could base our answer on which is more fundamental --Which came first, the chicken or the egg? The easy answer to this question is that the egg came first since reptiles laid eggs and birds evolved from reptiles. The egg is more fundamental and thus the chicken is the egg's way of making another egg. Similarly, entropy production and non-living FEDS preceded and are fundamental to life. Life is a subset of FEDS, not the other way around (Lineweaver 2006). Thus, life is a by-product of entropy production and statement "2)" is probably closer to the truth than "1)". Whether these ideas are precise enough to test more rigorously is an open question.

Quantum cosmologists are comparing their models of the origin of the universe with observations of the cosmic microwave background. Organic chemists are exploring alternatives to DNA as they try to create life in the laboratory. Molecular biologists are retracing phylogenetic relationships to the last universal common ancestor of all life to sniff out what the earliest life was like. Primatologist and evolutionary psychologists are 
trying to uncover the sources of human morality. Science has dispelled many myths and solved practical problems. The scientific method of observation, testing, hypothesis building, testing, rethinking and re-testing is, I think, the most powerful tool we have for producing knowledge about the origin of the universe, the origin of life, who we are, how we behave and the sources of our ethical behaviour. This knowledge has changed the way we behave, modified our self-opinions and changed the way we think we ought to behave. The conceptual realms of science and religion are increasingly overlapping magisteria.

\section{References}

Ayala, F.J. 1987 “The Biological Roots of Morality” Biology and Philosophy, 2, 235-252.

Barkow, J.H., Cosmides, L., Tooby, J. (eds) 1992, The Adapted Mind : Evolutionary Psychology and the Generation of Culture Oxford Univ. Press : Oxford

Bleier, R. 1984, Science and Gender: A Critique of Biology and Its Theories on Women Pergamon Press, Athene Series.

Brown, D.E. 1991 Human universals. McGraw-Hill:NY.

Coulson C.A., 1958 Science and Christian Belief Fontana:Great Britain p. 32.

Darwin, C.R. 1863 in letter to J.D. Hooker, March 29, 1863, cited in Darwin F., ed., The Life and Letters of Charles Darwin, [1898], Basic Books: New York NY, Vol. II., 1959, reprint, pp.202-203.

Darwin, C.R. 1871 The descent of Man, and selection in relation to sex. Murray:London.

Dawkins, R. 1976 The selfish gene. Oxford Univ. Press: Oxford.

deDuve, C. 1995 Vital Dust: The Origin and Evolution of Life on Earth. Basic Books NY.

Dennett, D. 2006 Breaking the Spell: Religion as a Natural Phenomenon, Viking: NY.

Dewar R.C. 2003 "Information theory explanation of the fluctuation theorem, maximum entropy production and self-organized criticality in non-equilibrium stationary states”. Phys. A Math, Gen 36:631.

Dewar R.C. 2005 Maximum Entropy Production and Non-Equilibrium Statistical Mechanics. in: A. Kleidon and R. Lorenz (eds) Non-equilibrium Thermodynamics and the Production of Entropy: Life, Earth and Beyond Springer:Berlin pp 41-53.

Feynmann, R. 1999 The Meaning of it All Perseus.

Fox, S. 1986 “Molecular Selection and Natural Selection” Quarterly Review of Biology, Vol 61, No. 3 (Sept 1986) pp 375-386.

Frautschi, S. 1982 “Entropy in an Expanding Universe”. Science 217:593-599.

Gillispie, G.C. 1973 The Edge of Objectivity.: Princeton Univ. Press:Princeton, N.J. pp 154-155.

Gould, S.J. 1992 “Impeach a Self-appointed Judge”, review of P.F. Johnson’s "Darwin on Trial” in Scientific American.

Gould, S.J. 1997 “Nonoverlapping magisteria”, Natural History 106, March, 1997, pp 16-22 Reprinted in Leonardo’s Mountain of Clams and the Diet of Worms, 1998, Harmony Books: NY pp 269-283.

Gould, S.J. 1999 Rocks of Ages Ballantine Books: NY.

Gray, R.D., Heaney, M. and Fairhall, S. 2003 "Evolutionary Psychology and the challenge of adaptive explanation" in: K. Sterelny and J. Fitness (eds) From Mating to Mentality: Evaluating Evolutionary Psychology. Psychology Press:London, pp. 247-268, Chapter 11.

Hall, N. 1999 “Science and Religion: Conflict or Conciliation” Skeptical Inquirer Special Issue on Science and Religion, July-August 1999.

Hamilton, W. D. 1975 “Innate social aptitudes of Man: an approach from evolutionary genetics”. in: R. Fox Biosocial anthropology, pp. 133-155. Halsted Press:NY.

Hamilton, W.D. 1998 The Narrow Roads of Gene Land, Vol 1, Evolution of Social Behavior. Oxford Univ. Press Oxford

Hazen, R.M. 2006 Genesis: The Scientific Quest for Life’s Origin Joseph Henry Press: Wash. DC.

Huxley, Thomas H. 1894 Evolution and Ethics and Other Essays. D. Appleton:NY.

Jones, S. 1997 In the Blood: God, Genes and Destiny Flamingo: London.

Johnson, P. 1991 Darwin on Trial Regnery Gateway Publishing: Wash.D.C.

Kinsey, A.C. 1953 Sexual Behaviour in the Human Female, W.B. Saunders:Philadelphia 
Kitzmiller v Dover Area School District 2005400 F. Supp. 2d 707, 735 (M.D. Pa 2005) (quoting testimony of John Haught) (also quoting Johnson's book Darwin on Trial).

Kleidon, A. and Lorenz, R. (eds) 2005 Non-equilibrium Thermodynamics and the Production of Entropy: Life, Earth and Beyond Springer:Berlin.

Kolb, E.W. and Turner, M.S. 1990 The Early Universe Addison Wesley:Redwood City CA.

Lahav, N. 1999 Biogenesis: Theories of Life's Origin, Oxford Univ. Press:Oxford

Lieberman, D. Tooby, J. and Cosmides, L. 2003 "Does morality have a biological basis? An empirical test of the factors governing moral sentiments relating to incest” Proc. R. Soc. Lond. B (2003) 270, 819-826.

Lineweaver, C.H. 2005 "Cosmological and Biological Reproducibility: Limits on the Maximum Entropy Production Principle” in: A. Kleidon and R. Lorenz (eds) Non-equilibrium Thermodynamics and the Production of Entropy: Life, Earth and Beyond Springer:Berlin pp 67-76.

Lineweaver, C.H. 2006 “We Have Not Detected Extraterrestrial Life, or Have We?” in: J. Seckbach (ed) Life as We Know it Springer:Dordrecht.

Lightman, A. Brawer, R. 1990 Origins: The lives and worlds of modern cosmologists. Harvard Univ. Press:Cambridge, MA.

Lunine, J.I. 2005 Astrobiology: An Intradisciplinary Approach Pearson:San Francisco.

Masters, W.H. and Johnson, V. 1966 Human Sexual Response Lippincott/Williams and Wilkins:NY

Mead, M. 1928 Coming of Age in Samoa. William Morrow:NY

Oates, D. 1988 “Social Darwinism and Natural Theodicy” Zygon, 24, No 4 Dec.

Pinker, S. 2002 The Blank Slate. Viking:NY.

Prigogine, I. 1980 From Being to Becoming. W.H. Freeman:NY.

Prigogine, I. and Stengers, I. 1984 Order out of Chaos Bantam NY.

Ridley, M. 1997 The Origins of Virtue, Human Instincts and the Evolution of Cooperation Viking:NY.

Sagan, D. and Whiteside, J.H. 2004 "Gradient Reduction Theory: Thermodynamics and the Purpose of Life" in: S.H. Schneider, J.R.Miller, E. Crist and P.J. Boston (eds) Scientists Debate Gaia: the Next Century, , MIT Press, Cambridge, MA p 173.

Sakharov, A.D. 1967 "Violations of CP Invariance, C Asymmetry and Baryon Asymmetry of the Universe" Pis’ma Zh. Eksp. Teor. Fiz 5, 32 [JETP Letters 5, 24, 1967].

Saunders, N. 2002 Divine Action and Modern Science Cambridge Univ. Press UK

Schneider, E.D. 2004 “Gaia: Towards a Thermodynamics of Life” in: S.H. Schneider, J.R.Miller, E. Crist and P.J. Boston (eds)Scientists Debate Gaia: the Next Century, MIT Press: Cambridge, MA p 45.

Schneider, E.D. and Kay, J.J. 1994 "Life as a Manifestation of the Second law of Thermodynamics" Mathematical and Computer Modeling, Vol 19, No. 6-8 pp 25-48.

Schneider, E.D. and Sagan, D. 2005 Into the Cool: Energy Flow, Thermodynamics and Life University of Chicago Press, Chicago Chapter 20 "Purpose in Life".

Schneider, S.H., Miller, J.R. Crist, E. and Boston, P.J. (eds) 2004 Scientists Debate Gaia: The Next Century MIT Press, Cambridge, MA.

Schroedinger, E. 1944 What is Life? Cambridge Univ. Press:UK.

Seckbach, J. Chela-Flores, J., Owen, T and Raulin, F. (eds) 2004 Life In The Universe: From the Miller Experiment to the Search for Life on Other Worlds Kluwer:Dordrecht.

Sober, E. and Wilson, D.S. 1998 Unto Others: The Evolution and Psychology of unselfish behavior. Harvard Univ. Press:Cambridge, MA.

Townes, C. 1966 “The Convergence of Science and Religion” Think, published by IBM March-April 1966. Vol 32, No 2.p 2-7.

Weinberg, S. 1977 The First three minutes, Basic Books:NY.

Weinberg, S. 2001 “A Designer Universe?” Skeptical Inquirer Sept/Oct 2001, 25:5 p 64.

White, M. and Gribbin, J. 2002 Stephen Hawking: A Life in Science Second Edition, Joseph Henry Press (p 201).

Williams, G. C. 1966 Adaptation and natural selection. Princeton Univ. Press:Princeton, NJ.

Williams, G.C. 1988a "Huxley’s Evolution and Ethics in Sociobiological Perspective”, Zygon, 23, 4, 383-407.

Williams, G.C. 1988b "Reply to Comments on "Huxley’s Evolution and Ethics in Sociobiological Perspective”, Zygon, 23, 4 383-407.

Wilson, E.O. 1976 Sociobiology Belknap Press of Harvard Univ. Press:Cambridge, MA.

Wilson, E.O. 1978 On Human Nature Harvard Univ. Press, Cambridge:MA. 